\title{
Impact of Protracted Displacement on Delay in the Diagnosis Associated with Treatment Outcomes: A Cross-sectional Study in Internally Displaced Tuberculosis Patients of Pakistan
}

Farman Ullah Khan 1,2,3,4 Faiz Ullah Khan 1,2,3,4, Khezar Hayat 1,2,3,4,5, Jie Chang 1,2,3,4, Muhammad Kamran ${ }^{6}$, Asad Khan 6, Usman Rashid Malik ${ }^{1,2,3,4}$,Asif Khan ${ }^{7}$, Yu Fang 1,2,3,4,

1. Department of Pharmacy Administration and Clinical Pharmacy, Xi'an Jiaotong University, Xi'an, China

2. Center for Drug Safety and Policy Research, Xi'an Jiaotong University, Xi'an, China

3. Shaanxi Center for Health Reform and Development Research, Xi'an Jiaotong University, Xi' an, China

4. Research Institute for Drug Safety and Monitoring, Institute of Pharmaceutical Science and Technology, China's Western Technological Innovation Harbor, Xi' an, China

5. Institute of Pharmaceutical Sciences, University of Veterinary and Animal Sciences, Lahore, Pakistan

6. Department of Pharmacy, Faculty of Biological Sciences, Quaid-i-Azam University Islamabad, Pakistan

7. District Bannu TB Control Program, Khyber Pakhtunkhwa, Pakistan

"Corresponding Author

Yu Fang, PhD, Professor

Department of Pharmacy Administration and Clinical Pharmacy

Xi'an Jiaotong University

No. 76 Yanta West Road

Xi'an, 710061

China

Phone: 0086-2982655132

Email: yufang@mail.xjtu.edu.cn 
Abstract: Human displacement is on the rise globally, and the increase in the burden of tuberculosis (TB) is also attributed to migrations worldwide. A significant number of such displacement occur in regions with considerably higher areas of TB burden. Displacements may delay in TB diagnosis and treatment, which possibly will lead to TB transmission among healthy individuals. In this study, we assessed the association of existing determinants after a protracted internal displacement of people with the delay in TB diagnosis and treatment outcomes. A cross-sectional study was conducted on internally displaced TB patients registered at selected health facilities in three urban districts of Pakistan from March 2019 to February 2020. The univariate and multivariate logistic regression model was used to assess the delay in diagnosis and treatment outcomes. IDPs with delay in initiation of treatment beyond 30 days were at high possibility of unsuccessful TB treatment outcomes (adjusted odds ratio AOR,2.60; 95\% CI 1.06-6.40). Analysis of factors that affect health seeker behavior and timely treatment showed a significant association $(\mathrm{p}<0.05)$ in-between age group 55-65 years (AOR, 2.66; 95\% CI 1.00-7.07), female patients (AOR, 2.42; 95\% CI 1.21-4.81), visited non-formal health provider (AOR, 8.81; 95\% CI3.99-19.46), self-medication (AOR, 2.72; $95 \%$ CI 1.37-5.37), poor knowledge of TB (AOR, 11.39; 95\% CI 3.31-39.1), and perceived stigma (AOR, 8.81; 95\% CI 3.99-19.4). Prolong delay in treatment was associated with unfavorable treatment outcomes among IDPs, more specifically. As migrants and IDPs are more likely to experience an interruption in care due to overall exclusion from social and health care services. Therefore, it is imperative to understand the barriers in providing public health care services, particularly in preventing and treating TB.

Keywords: Tuberculosis; Delay in diagnosis; Treatment outcomes; Internally displaced TB patients. 


\section{Introduction}

Tuberculosis (TB) is one of the leading causes of public health problems in developing countries [1]. According to the WHO 2020 TB report, about 7.1 million TB cases were reported. Only eight developing countries accounted for two-thirds of global TB cases. Pakistan was placed fifth among them [2]. The National TB Control Program of Pakistan (NTP) reported that the occurrence of TB cases annually was 630,000 (364/100,000 people), with death rates of 34/100,000 people [3]. WHO initiated End TB Strategy sets 2035 targets to achieve two goals, i.e., first, up to $90 \%$ annual reduction in the incidence rate, and second, 95\% reduction in TB deaths [4]. Although developments are being made, the progress has remained very slow in developing countries, and it is predicted that the world will not see an end to TB by 2035 as anticipated [5]. To achieve these goals, the WHO emphasize avoiding delays in the diagnosis and treatment of TB. Previous studies reported that the main barrier in TB control is undetected and untreated TB patients [6]. Delay in diagnosis and treatment will not only increase the risk of disease severity but will also promote its transmission in healthy individuals [7]. It is assessed that a single active TB case can communicate a disease to around 10-15 healthy people [8]. Therefore, it is necessary to take major steps to address the challenge of undetected people with TB at the national and subnational level in low- and middle-income countries (LMICs), especially in the most vulnerable TB populations. One of the main barriers in high TB burden countries is focusing on passive case detection of TB [9]. In passive case finding, people with probable TB come to a public health facility and are investigated for TB and the initiative comes from patients [10]. Due to this passive case detection, many factors contributed to the delay in the diagnosis and treatment of $\mathrm{TB}$, including poor socioeconomic status, awareness of symptoms of $\mathrm{TB}$, living in poor hygiene conditions, social stigma, disease, access to health facilities, and situations of displacement emergencies [11]. Another challenge to TB control is that multiple socioeconomic, cultural, environmental and political factors underpin the recent increase in human migration in developing nations [12]. These armed conflicts and population displacements, have negatively contributed to the changes in patterns of TB infection and have an alarming effect on its overall management [13]. Several crisis-related changes, such as living conditions, irregular residency, illiteracy, malnutrition, overcrowding, social isolation, and disruption in health services, are reasons to be considered as risk factors for TB [14-15]. The total number of people living in internal displacement reached a record 48 million by the end of 2020 [16]. In Pakistan, due to conflict and violence in 2014, a large segment of residents of former federally administered tribal area of North Waziristan (NW) were forced to move to adjoining areas of Khyber PakhtunKhwa such as Lakki Marwat, Bannu, Frontier Region of Bannu, and Dera Ismail Khan. United Nation Office has registered 961,000 IDPs from NW [17], who were forced to live in compromised living conditions and medical facilities [18]. 
Previous studies in Africa reported that armed conflicts had shown a negative impact on TB control programs due to interference with the goals of TB diagnosis and treatment [19]. In Ethiopia, TB patients from war-influenced regions delayed twice as long as to seek treatment[20]. Similarly, in Syria, forced mass displacement and humanitarian law violations have hampered the ability to diagnose, treat, and follow up TB cases [21]. The displaced population faces several new challenges to avoid TB risks and initiate proper treatment after displacement. Therefore, TB care demands a logical reaction to identify all the barriers to TB management. There is limited evidence on the influence of delay in diagnosis or treatment outcomes in internally displaced TB patients. Therefore, this study measured the association of existing determinants after prolonged internal displacement with delay in diagnosis and treatment outcomes.

\section{Materials and Methods:}

\subsection{Study design}

A cross-sectional study was conducted in four selected TB control centers to examine risk factors related to the delay in receiving diagnostic and treatment initiation among internally displaced TB patients (IDPs) registered in TB centers in the Khyber Pakhtunkhwa (KPK) province of Pakistan Figure 1.

\subsection{Study population and study setting}

TB patients registered in any of the selected TB centers (TBC), which were located in public hospitals of Bannu, Dera Ismail Khan, the former Frontier Region of Bannu, and Lakki Marwat and to whom the treatment schedule was to be completed during the study period (March 2019 to February 2020), were enrolled in this study. Those TB patients who a) refused to consent/participate, b) were younger than 18 years and older than 65 years of age, and c) could not recall the vital information required for the study were excluded from the final analysis. In order to avoid cross-contamination with local TB patients, the principal investigator reconfirmed the status of IDPs patients during the personal contact.

\subsection{Study tool}

Information from patients with tuberculosis was collected on a predesigned questionnaire, which had three subcategories of variables, namely sociodemographic factors (e.g., residency, gender, age, education, and socioeconomic status), clinical factors (e.g., history of symptoms, category of treatment, treatment outcomes and the number of patients with tuberculosis in the family member's per dwelling) and health-related factors (e.g., delay in diagnosis, health-seeking behaviors, and distance from the health care centre).

During patients' visits to the TBC, information about socio-demographics, displacement, and health-related factors were recorded on a questionnaire after getting the consent. Information about the patient's diagnosis, treatment type, treatment start date, and treatment outcomes were taken from the TB01 form, TB02 card, and TB03 register of TBC. The TB01 form is the main source of information, filled out for every 
newly diagnosed patient, and bears important administrative and treatment-related information. The copy of the information of TB01 is recorded in the registers (TB03) maintained at TBC and used to keep track of the entire TB patient in the area. TB02 is the TB patient's card, kept with patients, having general information about the patient and specific medical information about disease and treatment [22-23].

\subsection{Operational definitions}

According to WHO and NTP guidelines, treatment outcomes were classified as successful when the TB patient completed the treatment medication and/or 'cured,' while unsuccessful treatment outcomes were classified as treatment failure, treatment defaulter, died, transferred out, or registered patients whose outcomes are not known after completing the course [22, 24].

Based on starting of TB treatment after the onset of the symptom, patients were classified into "Delayed" and "Not-Delayed," taking 30 days (4 weeks) as cut-off points [25-26]. Diagnostic delay was taken as the time interval between the onset of the symptoms (major symptoms: cough, expectoration, and common symptoms: chest pain, mild fever, night sweats, poor appetite, and weight loss) and the date of labeling as TB patients after medical consultation. Duration to initial health-seeking was defined as the interim between the period of self-reported onset symptoms and the date of the first appearance at any health care facility (including hospital, TB dispensary, TB health centre, etc.). The initial healthcare-seeking delay was said delayed if they visited TB health-facility after the onset of symptoms for more than 3 weeks [27].

All the cases were followed until the earliest treatment outcome. A new case of pulmonary TB was defined as a patient who had been registered for less than 2 months before the start of the study or who was registered during the study period received (category I treatment), while category II patients are previously treated cases who are getting treatment after lost to follow up, relapse or failure. Both categories I and II receive first line of drugs, the difference is in addition of streptomycin and duration of treatment for category II patients [28-29].

After the appearance of symptoms, patients who sought self-medication (e.g., cough syrups, antipyretics, and antibiotics available over the counter) instead of visiting a health facility were taken as 'self-treatment.' A household contact was defined as a group of people who lived together, shared the same housekeeping arrangements, and ate together within one residence for at least 30 days prior to the identification of TB [30].

\subsection{Data analysis}

The sample size was calculated by using Rao soft calculator, using a 95\% significance level, and keeping the treatment adherence rate at $80 \%$ and $5 \%$ precision of the estimate. For data analysis, Social Sciences, version SPSS ${ }^{\circ}$ (IBM version 23) was used. Data were presented with percentages and frequencies for the 
socio-demographic treatment delay and outcomes. To assess the delay $>30$ and $\leq 30$ days and treatment outcomes among the participants, the univariate and then multivariate logistic regression model was used. The variables that were significant in the univariate analysis, we measured a stringent univariate $\mathrm{p}(<0.15)$ for addition of variables in the multivariate analysis model. All factors measured in univariate analysis were established on literature assessment and clinical importance with MDR TB. In developing the multivariate binary logistic regression, we have checked the collinearity and tolerance value for all those variables In case if independent variables had high correlation with each other (Variance inflation factor $=$ 10 and Tolerance value $>0.1$ ), one of them was apart from the final analysis model. Hosmere Lemeshow test was also applied for the standardization of the final logistic regression model [31-32]. Two different categories with binary variables were made for treatment outcome, i.e., successful and unsuccessful and delyed and not delyed according to WHO classification. Odds ratios with 95\% confidence intervals P-value $<0.05$ was considered significant and statistically important.

\section{Results:}

\subsection{Characteristics of participants}

A total of 391 TB patients were enrolled in the study. Of the total $49.6 \%$ TB patients were from the rural area, $35.3 \%$ from the camps, and $15.5 \%$ were from the city area. The majority of the TB patients were male $(52.2 \%)$ with a median age of $18-25$ years $(27.4 \%)$. The vast majority of respondents $(334,85.4 \%)$ were illiterate. Most of the reported $(134,34.3 \%)$ patients have to travel more than 30 kilometers to reach the health center. Also majority of the participants were faced with living in overcrowded situation (166, 42.5\%) Table 1.

Table 1: Sociodemographic characteristics of the TB patients enrolled in the study

\begin{tabular}{ll}
\hline Variables & IDPs N (\%) \\
\hline Residence & $194(49.6)$ \\
Village & $59(15.1)$ \\
City & $138(35.3)$ \\
Camp & \\
\hline Age & $107(27.4)$ \\
$18-25$ & $93(23.8)$ \\
$26-35$ & $47(12)$ \\
$36-45$ & $66(16.9)$ \\
$46-55$ & $78(19.9)$ \\
$56-65$ & \\
\hline Gender & $204(52.2)$ \\
Male & $187(47.8)$ \\
Female & \\
\hline Education & $57(14.6)$ \\
Literate & \\
\hline
\end{tabular}




\begin{tabular}{ll}
\hline Illiterate & $334(85.4)$ \\
\hline Place of living density & $66(16.8)$ \\
Low Density & $159(40.7)$ \\
High Density & $166(42.5)$ \\
Overcrowded & $32(8.2)$ \\
\hline Distance From Health Care Center & $92(23.5)$ \\
$\leq 5$ & $133(34)$ \\
$6-15$ Kilometer & $134(34.3)$ \\
16-30 Kilometer & \\
$>30$ Kilometer & $286(73.1)$ \\
\hline Health-seeking behavior & $105(26.9)$ \\
Visited non-formal health provider & \\
Visited a formal health provider & $147(37.6)$ \\
\hline Self-Medication & $244(62.4)$ \\
Yes & \\
No & $346(88.5)$ \\
\hline Category of treatment & $45(11.5)$ \\
Category I & \\
Category II & $49(12.5)$ \\
\hline Have you ever heard of TB before diagnosis? & $342(87.5)$ \\
Yes heard of TB & $74(18.9)$ \\
Not heard of TB & $317(81.1)$ \\
\hline Number of TB patients at House & $112(28.6)$ \\
Family members have TB & $279(71.4)$ \\
Family Member do not have TB & \\
\hline Perceived to be stigmatized & \\
Not stigmatized & \\
\hline Stigmatized & \\
\hline
\end{tabular}

\subsection{Health-seeking attitude}

More than half of the IDPs (59.1\%) got treatment after more than 30 days of delay since they first experienced TB symptoms. Most of these patients (391, 91.7\%) started TB treatment in TB diagnosis centers where they had also been diagnosed Figure 1. Most of the IDPs (286, $73.1 \%)$ had first visited the non-formal health facility and used different self-medication (37.6\%) before visiting a formal health care provider after the appearance of initial TB symptoms. Overall, $(342,87.5 \%)$ of the participants had inadequate knowledge on TB diagnosis, and only $12.5 \%$ were found to be knowledgeable, $71.4 \%$ of IDPs TB patients were identified with stigma related TB Table 1.

\subsection{Baseline TB signs and symptoms and transmission amoung patients}

Seventy-four (74) participants were identified as having more than one TB patient per house after the screening, which has the most likely probability of delay (AOR, 1.94; 95\%CI 0.78-4.79) Table 3. Three hundred and eighty-one patients $(97.4 \%)$ had a persistent cough and statistically significant high incidences 
of fever, chest pain, and, respectively, loss of body weight, with a complete delay of $>30$ days compared to those patients who have a delay of $\leq 30$ days Table 2 .

Table 2: TB Baseline signs and symptoms $n=391$ ( $\leq 30$ days vs. $>30$ )

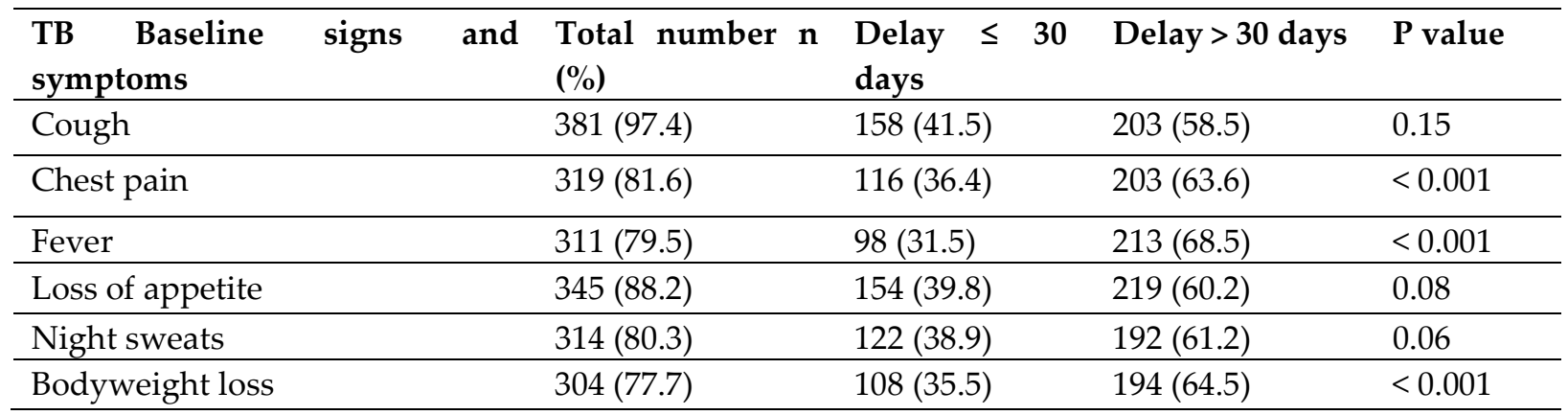

${ }^{*}$ Note: Depends upon on patients' response, more than one symptom, measured among patients who stated productive cough, $\mathrm{P} \leq 0.05$

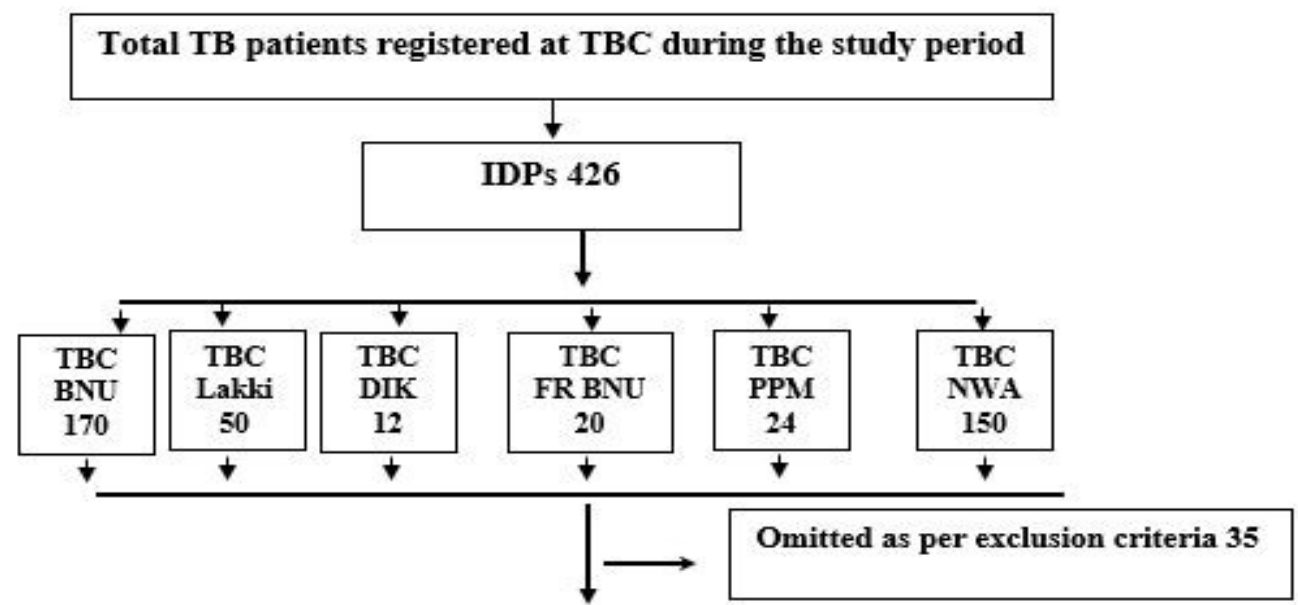

Total Number of TB Cases analyzed in the Study 391
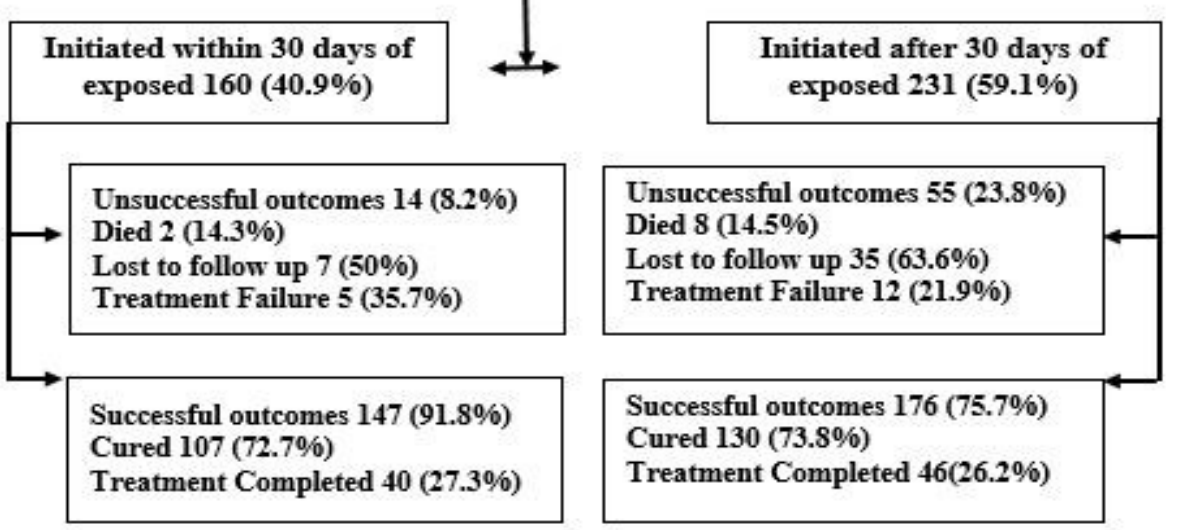

Figure 1. TBC (Tuberculosis Control Center), IDPs (Internally displaced TB patients), NW (North Waziristan), BNU (Bannu) F.R BNU (Frontier Region Bannu), DIK (Dera Ismail Khan), Treatment outcomes successful (Cured and treatment completed), Unsuccessful treatment outcomes 
(treatment failure, treatment defaulter, died), Omitted participants (transfer out or those registered patients whose outcomes are not known after completing the course).

\subsection{Predictors of delay}

Based on the analysis, $59.1 \%$ of TB IDPs patients have shown a delay > of 30 days Figure 1. Consequently, multiple linear regression resulted that there was a statistically significant difference in terms of patients' age considered as 18-25 age group as a reference, $46-55$ years odds ratio (AOR, 3.37; 95\% CI 1.21-9.37), and 56-65 years odds ratio (AOR, 2.66; 95\% CI 1.00-7.07), shows that both geriatric groups with higher odds ratios to initiate TB diagnosis on time within 30 days. The difference in delay between males and females was comparable in that female patients have 2.42 times the odds of a higher probability of diagnostic delay. There was also a statistically significant difference in delay between patients in terms of those patients who traveled a distance of more than $30 \mathrm{~km}$ that have the highest probability of delay in diagnosis with a 4.13 odds ratio (95\% CI 1.02-16.6), compared to those patients who traveled less than $30 \mathrm{~km}$. Patients who first visited non-formal health caregivers are more likely to delay getting proper treatment and diagnosis (AOR, 8.81; 95\% CI 3.99-19.46). Those who first practiced self-treatment with various therapies at their home were more likely with an odds ratio (AOR, 2.72; 95 \% CI 1.37-5.37), have experience longer delay. Additionally, the odds of knowledge about tuberculosis before starting this treatment were also more likely to delay in the health service seeking tuberculosis treatment (AOR, 11.39; 95\% CI 3.31-39.1). The patient's who experienced stigma has a more likely chance of delays in seeking diagnosis (AOR, 8.81; 95\% CI 3.99-19.4). Table 3.

Table 3: Logistic Regression analysis of factors associated with prolonged delay in treatment IDPs Predicted probability is $>30$.

\begin{tabular}{|c|c|c|c|c|}
\hline Factors & $\begin{array}{l}\text { Delay } \leq \text { than } 30 \\
\text { days }\end{array}$ & $\begin{array}{l}\text { Delay }>\text { than } \\
30 \text { days }\end{array}$ & Crude OR (95\%-CI) & $\begin{array}{l}\text { Adjusted OR }(95 \% \\
\text { CI) }\end{array}$ \\
\hline \multicolumn{5}{|c|}{ Residence } \\
\hline Village & $80(41.2)$ & $114(58.8)$ & Reference & Reference \\
\hline City & $47(79.7)$ & $12(20.3)$ & $0.34[0.27-0.93]$ & $0.42[0.16-1.18]$ \\
\hline Camp & $33(23.9)$ & $105(76.1)$ & $1.01[0.48-2.11]^{*}$ & $1.39[0.55-2.34]$ \\
\hline \multicolumn{5}{|l|}{ Age } \\
\hline $15-25$ & $65(60.7)$ & $42(39.3)$ & Reference & Reference \\
\hline $26-35$ & $42(45.2)$ & $51(54.8)$ & $1.87[1.07-3.30]$ & $2.17[0.84-5.34]$ \\
\hline $36-45$ & $17(36.2)$ & $30(63.8)$ & $2.73[1.34-5.55]$ & $1.13[0.40-3.27]$ \\
\hline $46-55$ & $15(22.7)$ & $51(77.3)$ & $5.26[2.62-10.3]^{*}$ & $3.37[1.35-9.37]^{*}$ \\
\hline $56-65$ & $21(26.9)$ & $57(73.1)$ & $4.20[2.23-7.91]^{*}$ & $2.66[1.00-7.07]^{*}$ \\
\hline \multicolumn{5}{|l|}{ Gender } \\
\hline Male & $110(53.9)$ & $94(46.1)$ & Reference & Reference \\
\hline Female & $50(26.7)$ & $137(73.7)$ & $3.20[2.09-4.90]^{*}$ & $2.42[1.21-4.81]^{*}$ \\
\hline \multicolumn{5}{|c|}{ Education } \\
\hline Literate & $24(42.1)$ & $33(57.9)$ & Reference & Not included \\
\hline
\end{tabular}




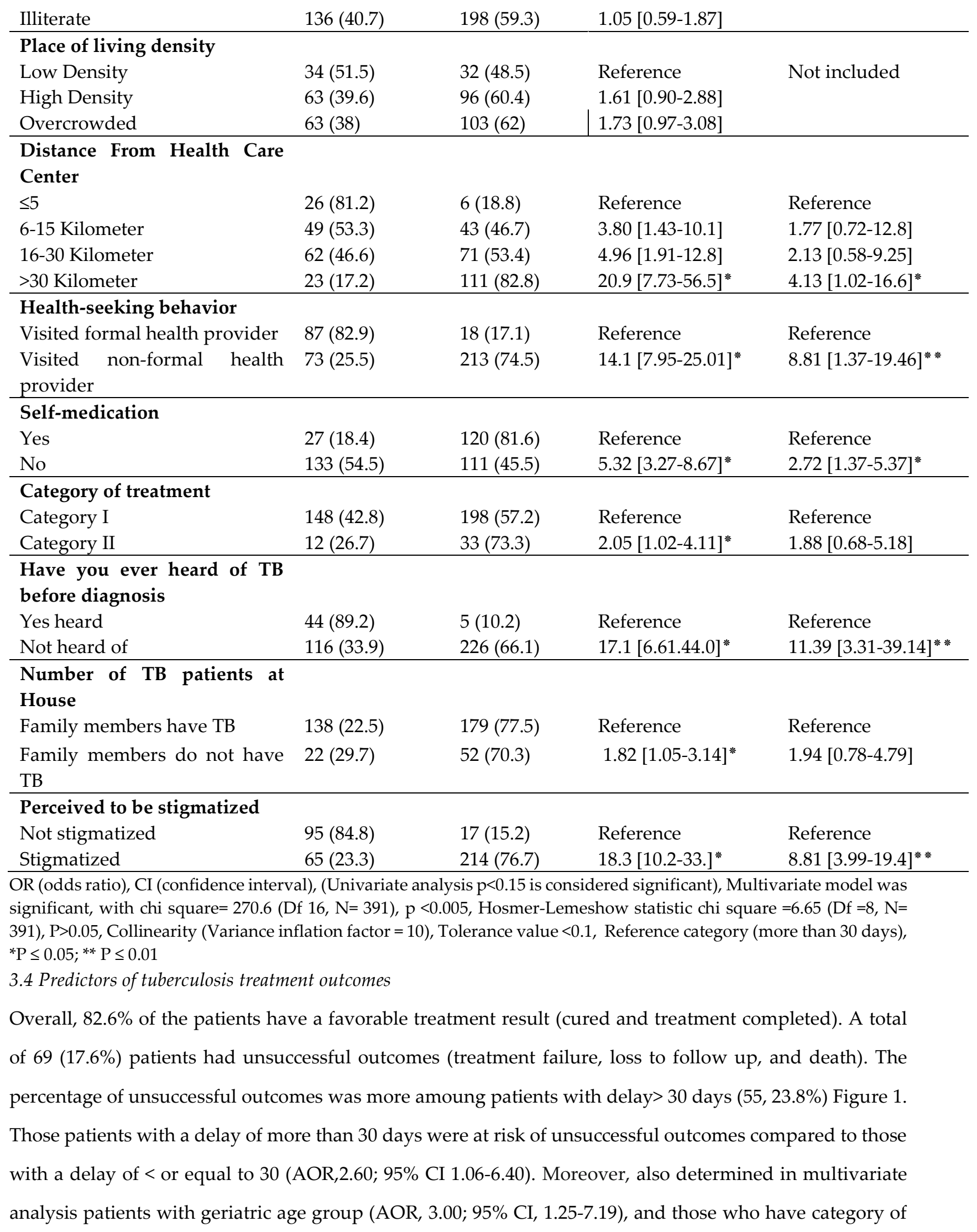


treatment II (AOR, 4.80; 95\% CI 1.99-8.34), were significantly associated with unsuccessful treatment outcomes Table 4 .

Table 4: Predictors associated with treatment outcomes in internally displaced TB patients

\begin{tabular}{|c|c|c|c|c|}
\hline Variables & IDPs n (\%) & USO n (\%) & Crude OR (95\%-CI) & Adjusted OR (95\%-CI) \\
\hline \multicolumn{5}{|l|}{ Delay diagnosis } \\
\hline Less than 30 days & $160(39.9)$ & $13(18.8)$ & Reference & Reference \\
\hline More than 30 days & $231(57.6)$ & $56(81.2)$ & $3.61[1.94-6.8]^{*}$ & $2.60[1.06-6.40]^{*}$ \\
\hline \multicolumn{5}{|l|}{ Residency } \\
\hline Village & $194(49.6)$ & $29(42.1)$ & Reference & Reference \\
\hline City & $59(15.1)$ & $7(10.1)$ & 0.76 [0.31-1.85] & $1.50[0.55-4.08]$ \\
\hline Camp & $138(35.3)$ & $33(47.8)$ & $1.78[1.02-3.11]^{*}$ & $1.41[0.76-2.64]$ \\
\hline \multicolumn{5}{|l|}{ Gender } \\
\hline Male & $204(52.7)$ & $31(44.9)$ & Reference & Not included \\
\hline Female & $187(47.8)$ & $38(55.1)$ & $1.42[0.84-2.40]$ & \\
\hline \multicolumn{5}{|l|}{ Age } \\
\hline $15-25$ & $107(27.4)$ & $10(14.5)$ & Reference & Reference \\
\hline $26-35$ & $93(23.8)$ & $10(14.5)$ & $1.16[0.46-0.29]$ & $0.97[0.36-2.57]$ \\
\hline $36-45$ & 47 (12) & $7(10.10)$ & 1.69 [0.60-4.77] & $1.26[0.42-3.76]$ \\
\hline $46-55$ & $66(16.9)$ & $20(29.0)$ & $4.21[1.82-9.73]^{*}$ & $3.15[1.27-7.80]^{*}$ \\
\hline $56-65$ & $78(19.9)$ & $22(31.9)$ & $3.81[1.68-8.62]^{*}$ & $3.00[1.25-7.19]^{*}$ \\
\hline \multicolumn{5}{|l|}{ Education } \\
\hline Literate & $57(14.6)$ & $33(47.8)$ & Reference & Not Included \\
\hline Illiterate & $334(85.4)$ & $36(52.1)$ & $1.00[0.48-2.11]$ & \\
\hline \multicolumn{5}{|l|}{$\begin{array}{l}\text { Number of Room/Tents Per } \\
\text { house }\end{array}$} \\
\hline Low Density & $66(16.9)$ & $11(15.9)$ & Reference & Not Included \\
\hline High Density & $159(40.7)$ & $22(31.9)$ & $0.80[0.36-1.76]$ & \\
\hline Overcrowded & $166(42.5)$ & $36(52.2)$ & $1.38[0.65-2.91]$ & \\
\hline \multirow{2}{*}{\multicolumn{5}{|c|}{$\begin{array}{l}\text { Distance From Health Care } \\
\text { Center }\end{array}$}} \\
\hline & & & & \\
\hline$\leq 5$ & $32(8.2)$ & $4(5.8)$ & Reference & Not Included \\
\hline 6-15 Kilometer & $92(23.5)$ & $14(20.3)$ & $1.25[0.38-4.13]$ & \\
\hline 16-30 Kilometer & $133(34)$ & $17(24.6)$ & $1.02[0.32-3.28]$ & \\
\hline >30 Kilometer & $134(34.3)$ & $34(49.3)$ & $2.38[0.77-7.27]$ & \\
\hline \multicolumn{5}{|l|}{ Health-seeking behavior } \\
\hline $\begin{array}{l}\text { Visited a formal health } \\
\text { provider }\end{array}$ & 105 (26.9) & $10(14.5)$ & Reference & Reference \\
\hline $\begin{array}{l}\text { Visited non-formal health } \\
\text { provider }\end{array}$ & $286(73.1)$ & $59(85.5)$ & $1.72[0.89-3.30]^{*}$ & $1.43[0.60-3.35]$ \\
\hline \multicolumn{5}{|l|}{ Self-medication } \\
\hline Yes & $147(37.6)$ & $37(53.6)$ & Reference & Reference \\
\hline No & $244(62.4)$ & $32(46.4)$ & $1.79[1.06-3.03]^{*}$ & $1.42[0.77-2.62]$ \\
\hline \multicolumn{5}{|l|}{$\begin{array}{l}\text { Have you ever heard of TB } \\
\text { before diagnosis? }\end{array}$} \\
\hline Yes heard & $49(12.5)$ & $6(8.7)$ & Reference & Reference \\
\hline
\end{tabular}




\begin{tabular}{|c|c|c|c|c|}
\hline Not heard of & $342(87.5)$ & $63(91.3)$ & $1.61[0.66-3.98]^{*}$ & $1.40[0.49-4.008]$ \\
\hline \multicolumn{5}{|l|}{$\begin{array}{l}\text { Number of TB patients at } \\
\text { House }\end{array}$} \\
\hline Family members have TB & $74(18.9)$ & $20(28.9)$ & Reference & Not Included \\
\hline $\begin{array}{l}\text { Family members do not have } \\
\text { TB }\end{array}$ & $317(81.1)$ & $49(71.8)$ & $0.80[0.42-1.52]$ & \\
\hline \multicolumn{5}{|l|}{ Category of treatment } \\
\hline Category I & $346(88.5)$ & $49(71)$ & Reference & Reference \\
\hline Category II & $45(11.5)$ & $20(29)$ & $4.84[2.50-9.39]^{*}$ & $4.80[1.99-8.34]^{*}$ \\
\hline \multicolumn{5}{|l|}{ Perceived to be stigmatized } \\
\hline Not stigmatized & $112(28.6)$ & $12(17.4)$ & Reference & Not Included \\
\hline Stigmatized & $279(71.4)$ & $57(82.6)$ & $2.14[1.10-4.16]$ & \\
\hline
\end{tabular}

USO (unsuccessful outcomes), OR (odds ratio), CI (confidence interval), (Univariate analysis $p<0.15$ is considered significant), Multivariate model was significant, with chi square= 49.34 (Df 11, $N=391$ ), $p<0.005$, Hosmer-Lemeshow statistic chi square $=7.88(\mathrm{Df}=8, \mathrm{~N}=391$ ), $\mathrm{P}>0.05$, Collinearity (Variance inflation factor $=10$ ), Tolerance value $\mathrm{P}<0.1$, Reference category (Unsuccesful outcomes), ${ }^{*} \mathrm{P} \leq 0.05 ;{ }^{* *} \mathrm{P} \leq 0.01$

\section{Discussion:}

In this study, we identified a relationship between total delay and unsuccessful treatment outcomes. The rate of successful treatment outcomes was lowered from the WHO global target rate of $85 \%$ [33]. Most of the participants with a prolonged delay of $>30$ days were found to have unsuccessful treatment outcomes than participants with a delay of $\leq 30$ days. However, delay in initiation of anti-TB medication results in various serious complications, which may significantly affect the treatment outcomes [34]. Unsuccessful treatment outcomes are associated with drug resistance against anti-TB drugs that may enhance morbidity, mortality, disease transmission and treatment failure rate [35]. The results of this study underscore the need for rapid identification and management of tuberculosis, especially in a highly vulnerable population such as IDPs who were exposed to prolonged delays of $>30$ days. The analysis showed a statistically significant association between prolongs treatment delay and unsuccessful treatment outcomes which is inconsistent with the findings of earlier studies [7,36-37]. This put forward the need for an early finding of TB cases to ensure better results among IDPs and lessen the TB burden. The prolonged delay in diagnosis and treatment worsens the disease progression and symptoms [38]. Following the onset of symptoms, reporting first to the TB centre was measured as a reference point in this study, an approach reported in the 39 previous studies [39]. We found that the prolonged delay of $>30$ days was more among the IDPs TB patients. Accordance with the previous studies where the median delay of patients was 4 weeks and 6 weeks, respectively $[9,40-42]$ and lower than studies conducted in Ethiopia, India and Chad [43-45]. The disagreement between these studies may be due to TB patients from different countries and their health systems, policies and infrastructure, and differences in sociodemographic characteristics. Health careseeking behavior is a complex process influenced by many external and internal factors. IDPs showed a 
prolonged delay in seeking care because $73.1 \%$ of TB patients lean towards less expensive nonformal health services and $37.6 \%$ practiced self-medication, both leading to poor treatment outcomes. This is in line with the finding of previous studies conducted in conflict and non-conflict regions that non-formal healthcare providers play a significant role in delay [46-48]. Furthermore, a significant association was observed between self-medication and delay, which is consistent with previous studies conducted [49-50]. Furthermore, the distance from the TB centre of more than $30 \mathrm{~km}$ is responsible for an unacceptable delay in patient care. This is supported by a considerable number of studies and systematic reviews and metaanalyses that specified patients who travel a long distance to reach healthcare services experienced longer delays [51-53].

Our findings propose that a coordinated effort is needed to increase public awareness of the importance of the right diagnosis at the right time and seek health in the right formal health care centers. In this study, due to lack of public awareness, the majority of the IDPs had no defined knowledge of TB treatment and diagnosis and have been living in a single shared room or in camps that have significantly affected patients reporting diagnosis and timely initiation of treatment. The findings of the current study are in agreement with previous studies published elsewhere [29, 40, 54-55]. Our finding supported that lack of TB knowledge may lead to a patient unwillingness to seek suitable health care.

Our study also observed that patients over 55 years of age and women have an increased proablity of prolonged delay. Older patients and women in this part of the world generally depend on others, so it can be challenging for them to seek medical care when necessary. However, similar to our study, a systematic review of 45 studies from Asia stated that older age and females are strongly associated with delays in the diagnosis of TB [11, 56-57]. Females' tendency to delay has been attributed to their restricted socio-cultural environment in Pakistan, decision-making power, the burden of domestic works, illiteracy, and distance from health care centres [58].

WHO reported that the most important determinant of TB diagnosis and treatment delay is stigma [59]. We found that prolonged patient delay was common in those who reported any form of stigma. Our findings are similar to those for other countries; studies observed stigma as a common obstacle in seeking early treatment [60-62]. Available evidence shows that interventions are needed to reduce the TB stigma, and there is a need for patient-centered TB care [63].

The delay in diagnosing TB patients is also related to the increased spread of the disease in healthy individuals [43, 47]. Time spent in crowded camps increases the risk of TB exposure and infection. Timely identification is very important for TB control because delayed diagnosis is known to be linked with higher TB transmission rates [47]. This may be one of the reasons that the participants from IDPs accounted for 
more TB cases and experienced a higher rate of TB cases in their families. The result of our study is similar in this context to other studies [47, 64].

The most prominent symptoms associated with the development of TB were the appearance of a persistent cough. However, a significant percentage of TB patients were experiencing symptoms such as fever, chest pain, and weight loss, particularly in patients whose diagnosis and treatment were delayed for more than 30 days. The result of this study is in agreement with previous studies [7, 65].

This study also has several limitations. First, the reporting interval of symptoms is based on the patient's recall and interpretation, and recall bias is a serious issue for an accurate estimate in delay. Unfortunately, there is no feasible method to deal with the issue of recall bias except to include the recently treated patients. The response of the inaccessible TB patients, who met the inclusion criteria, could not be analyzed. Hence, the outcomes cannot be summed up to all TB patients in other parts of the country.

The study has several pros and cons. As far as the significance of the study is concerned, this is the main study in Pakistan that has tried to explore the impact and predictors of delay and TB treatment results in IDPs. Therefore, the findings of our study might be utilized as standard information for upcoming studies. The study furthermore highlighted the need for intervention in TB prevention and control strategies, especially among IDPs. To provide them timely TB related to care after displacement. Care-seeking behavior and delays in TB diagnosis in Pakistani IDPs will likely be further trampled by the beginning of the COVID-19 pandemic. This statement is supported by a WHO report that stated TB care could cause an additional half a million TB deaths [66].

\section{Conclusions:}

A significant challenge for TB control is delayed case identification. This delay in TB diagnosis and treatment initiation should be reduced to the least possible in case of human displacements. As migrants and internally displaced persons are more likely to experience the interrupted care because of the overall exclusion from social and public health services. Therefore, it is imperative to understand the barriers in providing public health care services, particularly in preventing and treating TB. Community engagement and multisectoral collaboration can improve the delivery of critical health services during displacement. Empowering the patient by increasing the patient-centred approach involves the crises emergency affected TB patient in the decision-making. The study further indicates that future TB control policies should address all issues of IDP TB patients in the country.

Author's contribution: Conceptualization, methodology, FUK (Farman Ullah Khan) and YF.; software, AK.; formal analysis MK and URM.; data curation AK (Asif Khan) and FUK (Faiz Ullah Khan).; writing original draft preparation, FUK (Farman Ullah Khan).; writing review and editing, JC and FUK (Faiz Ullah 
Khan) and KH.; funding acquisition resources and supervision YF.; YF and all authors have read and agreed to the published version of the manuscript."

Funding: This work was funded by the "Young Talent Support Plan"; by the "High Achiever Plan" of the Health Science Center, Xi'an Jiaotong University; and by the Central University Basic Research Fund (2015qngz05)

Institutional Review Board Statement: The TB control program granted the approval permission to conduct the study (NO, F6-1/NTP-ADMIN). In addition, the study was ethically approved by Xian Jiaotong University, Health Science Center Biology Scientific Research Ethics Committee (2019-1257).

Informed Consent Statement: The informed consent was obtained from the study participants, who were ensured regarding the privacy of all the information. The participants/family members either signed the consent form or gave verbal consent (in case of illiterate).

Data Availability Statement: The data sets used and analyzed during the current study are available from the corresponding author on reasonable request.

Acknowledgments: The authors would like to acknowledge the DOTs clinic staff, Dr Israr Khan, Dr Faraz Khan and TB patients who are contributing to or are involved in this project.

Conflicts of Interest: The authors declare no conflict of interest. 


\section{References}

1. Ullah, S.; Ullah, O.; Khan, M. A.; Gul, T. Optimal control analysis of tuberculosis (TB) with vaccination and treatment. The European Physical Journal Plus 2020, 135, 1-27.

2. WHO, G. Global tuberculosis report 2020. Glob. Tuberc. Rep. 2020, Avaliable online: who.int/iris/bitstream/handle/10665/336069/9789240013131 (accessed on 24-1-2021).

3. Khan, A. H. Tuberculosis control in Sindh, Pakistan: Critical analysis of its implementation. Journal of infection and public health 2017, 10, 1-7.

4. $\quad$ Uplekar, M.; Weil, D.; Lonnroth, K.; Jaramillo, E.; Lienhardt, C.; Dias, H. M.; Falzon, D.; Floyd, K.; Gargioni, G.; Getahun, H. WHO's new end TB strategy. The Lancet 2015, 385, 1799-1801.

5. Chakaya, J.; Khan, M.; Ntoumi, F.; Aklillu, E.; Fatima, R.; Mwaba, P.; Kapata, N.; Mfinanga, S.; Hasnain, S. E.; Katoto, P. D. Global Tuberculosis Report 2020-Reflections on the Global TB burden, treatment and prevention efforts. International Journal of Infectious Diseases 2021.

6. Almeida, C. P. B. d.; Skupien, E. C.; Silva, D. R. Health care seeking behavior and patient delay in tuberculosis diagnosis. Cadernos de saude publica 2015, 31, 321-330.

7. Gebreegziabher, S. B.; Bjune, G. A.; Yimer, S. A. Total delay is associated with unfavorable treatment outcome among pulmonary tuberculosis patients in west Gojjam zone, Northwest Ethiopia: a prospective cohort study. PloS one 2016, 11, e0159579.

8. $\quad$ Datiko, D. G.; Jerene, D.; Suarez, P. Patient and health system delay among TB patients in Ethiopia: Nationwide mixed method cross-sectional study. BMC Public Health 2020, 20, 1-10.

9. Fuge, T. G.; Bawore, S. G.; Solomon, D. W.; Hegana, T. Y. Patient delay in seeking tuberculosis diagnosis and associated factors in Hadiya Zone, Southern Ethiopia. BMC research notes 2018, 11, 1-6.

10. Shewade, H. D.; Gupta, V.; Satyanarayana, S.; Pandey, P.; Bajpai, U.; Tripathy, J. P.; Kathirvel, S.; Pandurangan, S.; Mohanty, S.; Ghule, V. H. Patient characteristics, health seeking and delays among new sputum smear positive TB patients identified through active case finding when compared to passive case finding in India. PloS one 2019, 14, e0213345.

11. Owolabi, O. A.; Jallow, A. O.; Jallow, M.; Sowe, G.; Jallow, R.; Genekah, M. D.; Donkor, S.; Wurrie, A.; Kampmann, B.; Sutherland, J. Delay in the diagnosis of pulmonary tuberculosis in The Gambia, West Africa: A cross-sectional study. International Journal of Infectious Diseases 2020, 101, 102-106.

12. Dhavan, P.; Dias, H.; Creswell, J.; Weil, D. An overview of tuberculosis and migration. The international journal of tuberculosis and lung disease 2017, 21, 610-623.

13. Ismail, M. B.; Rafei, R.; Dabboussi, F.; Hamze, M. Tuberculosis, war, and refugees: spotlight on the Syrian humanitarian crisis. PLoS pathogens 2018, 14, e1007014.

14. Gilbert, R. L.; Antoine, D.; French, C.; Abubakar, I.; Watson, J.; Jones, J. The impact of immigration on tuberculosis rates in the United Kingdom compared with other European countries. The international journal of tuberculosis and lung disease 2009, 13, 645-651.

15. Pelissari, D. M.; Diaz-Quijano, F. A. Household crowding as a potential mediator of socioeconomic determinants of tuberculosis incidence in Brazil. PloS one 2017, 12, e0176116.

16. Center, I. D. M. Global Report on Internal Displacement, 2021. Noruega: Norwegian Refugee Council 2021.

17. Hameed, N. Struggling IDPS of North Waziristan in the Wake of Operation Zarb-e-Azb. NDU Journal. Retrieved from http://wwww. ndu. edu. pk/issra/issra_pub/articles/ndujournal/NDU-Journal-2015/05Struggling-IDPs. pdf 2015.

18. Javaid, U. Operation Zarb-e-Azb: A Successful Initiative to Curtail Terrorism. South Asian Studies 2015, 30, 43.

19. Coninx, R. Tuberculosis in complex emergencies. Bulletin of the World Health Organization 2007, 85, 637-640.

20. Kimbrough, W.; Saliba, V.; Dahab, M.; Haskew, C.; Checchi, F. The burden of tuberculosis in crisisaffected populations: a systematic review. The Lancet infectious diseases 2012, 12, 950-965. 
21. Abbara, A.; Almalla, M.; AlMasri, I.; AlKabbani, H.; Karah, N.; El-Amin, W.; Rajan, L.; Rahhal, I.; Alabbas, M.; Sahloul, Z. The challenges of tuberculosis control in protracted conflict: the case of Syria. International Journal of Infectious Diseases 2020, 90, 53-59.

22. NTP. Reporting and Recording Tools: National TB Control Program, Pakistan. Available online: http://ntp.gov.pk/wp-content/uploads/2020/02/TB.pdf (accessed on 24-1-2021).

23.NTP. PPM DOTS:Training courses on DOTS for doctors at private hospitals/clinics; National TB Control Program: 2008. Accessed on 24-1-2021.

24. WHO, Definitions and reporting framework for tuberculosis 2013. World Health Organization, Geneva, Switzerland Available online:t https://apps.who.int/iris/bitstream/handle/10665 (accessed on 26 December 2020).

25. Mesfin, M. M.; Newell, J. N.; Walley, J. D.; Gessessew, A.; Madeley, R. J. Delayed consultation among pulmonary tuberculosis patients: a cross sectional study of 10 DOTS districts of Ethiopia. BMC Public Health 2009, 9, 53.

26. Asres, A.; Jerene, D.; Deressa, W. Delays to treatment initiation is associated with tuberculosis treatment outcomes among patients on directly observed treatment short course in Southwest Ethiopia: a follow-up study. BMC pulmonary medicine 2018, 18, 1-11.

27. Belay, M.; Bjune, G.; Ameni, G.; Abebe, F. Diagnostic and treatment delay among Tuberculosis patients in Afar Region, Ethiopia: a cross-sectional study. BMC public health 2012, 12, 369.

28. PHOA, L. L.; Teleman, M. D.; WANG, Y. T.; Chee, C. B. Characteristics of patients with delayed diagnosis of infectious pulmonary tuberculosis. Respirology 2005, 10, 196-200.

29. Li, Y.; Ehiri, J.; Tang, S.; Li, D.; Bian, Y.; Lin, H.; Marshall, C.; Cao, J. Factors associated with patient, and diagnostic delays in Chinese TB patients: a systematic review and meta-analysis. BMC medicine 2013, $11,156$.

30. Rehman, S.; Kashif Munir, M.; Iqbal, R.; Ahmed Salam, A.; Saeed, S.; Masud, F.; Aasim, M. Active Case Detection Among Household Contacts of Multi Drug Resistant Tuberculosis Patients in a Tertiary Care Setting. Pakistan Journal of Medical Research 2014, 53.

31. Steyerberg, E. W. Applications of prediction models. In Clinical prediction models; Springer: 2009; pp. 11-31.

32. Pallant, J. SPSS survival manual: A step by step guide to data analysis using IBM SPSS; Routledge: 2020.

33. WHO, W. H. O. Global tuberculosis report 2015; World Health Organization: 2015. World Health Organization, Geneva, Switzerland Available online:t https://apps.who.int/iris/bitstream/handle/10665 (accessed on 24.1. 2021).

34. Hamza, A.; Demissie, M.; Gare, S.; Teshome, G. Delay in Tuberculosis Diagnosis among Tuberculosis Patients at the Three Hospitals: Asella, Robe and Abomsa of Arsi Zone, Oromia Regional State. Open Access Library Journal. 2015; 2, e1947. Open Access Library Journal 2015, 2, 1.

35. Kuznetsov, V. N.; Grjibovski, A. M.; Mariandyshev, A. O.; Johansson, E.; Bjune, G. A. Two vicious circles contributing to a diagnostic delay for tuberculosis patients in Arkhangelsk. Emerging health threats journal 2014, 7, 24909.

36. Vree, M.; Huong, N. T.; Duong, B. D.; Sy, D. N.; Cobelens, F. G.; Borgdorff, M. W. High mortality during tuberculosis treatment does not indicate long diagnostic delays in Vietnam: a cohort study. BMC Public Health 2007, 7, 210.

37. Helfinstein, S.; Engl, E.; Thomas, B. E.; Natarajan, G.; Prakash, P.; Jain, M.; Lavanya, J.; Jagadeesan, M.; Chang, R.; Mangono, T. Understanding why at-risk population segments do not seek care for tuberculosis: a precision public health approach in South India. BMJ global health 2020, 5, e002555.

38. Virenfeldt, J.; Rudolf, F.; Camara, C.; Furtado, A.; Gomes, V.; Aaby, P.; Petersen, E.; Wejse, C. Treatment delay affects clinical severity of tuberculosis: a longitudinal cohort study. BMJ open 2014, 4, e004818. 
39. Storla, D. G.; Yimer, S.; Bjune, G. A. A systematic review of delay in the diagnosis and treatment of tuberculosis. BMC Public Health 2008, 8, 15.

40. Wang, Y.; Long, Q.; Liu, Q.; Tolhurst, R.; Tang, S. Treatment seeking for symptoms suggestive of TB: comparison between migrants and permanent urban residents in Chongqing, China. Tropical Medicine E International Health 2008, 13, 927-933.

41. Saqib, S. E.; Ahmad, M. M.; Amezcua-Prieto, C.; Virginia, M.-R. Treatment Delay among Pulmonary Tuberculosis Patients within the Pakistan National Tuberculosis Control Program. The American journal of tropical medicine and hygiene 2018, 99, 143-149.

42. Buregyeya, E.; Criel, B.; Nuwaha, F.; Colebunders, R. Delays in diagnosis and treatment of pulmonary tuberculosis in Wakiso and Mukono districts, Uganda. BMC Public health 2014, 14, 1-10.

43. Madebo, T.; Lindtjorn, B. Delay in treatment of pulmonary tuberculosis: an analysis of symptom duration among Ethiopian patients. MedGenMed: Medscape general medicine 1999, E6-E6.

44. Demissie, M.; Lindtjorn, B.; Berhane, Y. Patient and health service delay in the diagnosis of pulmonary tuberculosis in Ethiopia. BMC Public Health 2002, 2, 1.

45. Purty, A. J.; Chauhan, R. C.; Natesan, M.; Cherian, J.; Singh, Z.; Sharma, Y. Patient and health system delays among adult smear-positive tuberculosis patients diagnosed at medical colleges of Puducherry in south India. Indian journal of public health 2016, 60, 77.

46. Gebreegziabher, S. B.; Bjune, G. A.; Yimer, S. A. Patients' and health system's delays in the diagnosis and treatment of new pulmonary tuberculosis patients in West Gojjam Zone, Northwest Ethiopia: a cross-sectional study. BMC infectious diseases 2016, 16, 1-13.

47. Gele, A. A.; Bjune, G. A. Armed conflicts have an impact on the spread of tuberculosis: the case of the Somali Regional State of Ethiopia. Conflict and health 2010, 4, 1-6.

48. Ayalew, Y. E.; Yehualashet, F. A.; Bogale, W. A.; Gobeza, M. B. Delay for Tuberculosis Treatment and Its Predictors among Adult Tuberculosis Patients at Debremarkos Town Public Health Facilities, North West Ethiopia. Tuberculosis research and treatment 2020, 2020.

49. Chen, T.-C.; Lu, P.-L.; Lin, C.-Y.; Lin, W.-R.; Chen, Y.-H. Fluoroquinolones are associated with delayed treatment and resistance in tuberculosis: a systematic review and meta-analysis. International Journal of Infectious Diseases 2011, 15, e211-e216.

50. Rabin, A.; Kuchukhidze, G.; Sanikidze, E.; Kempker, R.; Blumberg, H. Prescribed and selfmedication use increase delays in diagnosis of tuberculosis in the country of Georgia. The International journal of tuberculosis and lung disease 2013, 17, 214-220.

51. Xingxing, L.; Xun, L.; Tao, L.; Jianjun, Y.; Mengxian, Z.; Yu, Z.; Chengfeng, Y.; Wei, C.; Liping, Z. Factors associated with health care-seeking delay and treatment delay in tuberculosis patients in Shishou and Badong of Hubei. 疾病监测 2021, 36, 1-7.

52. Santos, E.; Felgueiras, Ó.; Oliveira, O.; Duarte, R. Diagnosis delay of tuberculosis in the Huambo province, Angola. Pulmonology 2018, 24, 294-299.

53. Alene, M.; Assemie, M. A.; Yismaw, L.; Gedif, G.; Ketema, D. B.; Gietaneh, W.; Chekol, T. D. Patient delay in the diagnosis of tuberculosis in Ethiopia: a systematic review and meta-analysis. BMC infectious diseases 2020, 20, 1-9.

54. Wei, X.; Chen, J.; Chen, P.; Newell, J. N.; Li, H.; Sun, C.; Mei, J.; Walley, J. D. Barriers to TB care for rural-to-urban migrant TB patients in Shanghai: a qualitative study. Tropical Medicine $\mathcal{E}$ International Health 2009, 14, 754-760.

55. Huffman, S. A.; Veen, J.; Hennink, M. M.; McFarland, D. A. Exploitation, vulnerability to tuberculosis and access to treatment among Uzbek labor migrants in Kazakhstan. Social science \& medicine 2012, 74, 864-872. 
56. Peri, A. M.; Bernasconi, D. P.; Galizzi, N.; Matteelli, A.; Codecasa, L.; Giorgio, V.; Di Biagio, A.; Franzetti, F.; Cingolani, A.; Gori, A. Determinants of patient and health care services delays for tuberculosis diagnosis in Italy: a cross-sectional observational study. BMC infectious diseases 2018, 18, 1-11.

57. Cai, J.; Wang, X.; Ma, A.; Wang, Q.; Han, X.; Li, Y. Factors associated with patient and provider delays for tuberculosis diagnosis and treatment in Asia: a systematic review and meta-analysis. PloS one 2015, 10, e0120088.

58. Saqib, M. A.; Awan, I. N.; Rizvi, S. K.; Shahzad, M. I.; Mirza, Z. S.; Tahseen, S.; Khan, I. H.; Khanum, A. Delay in diagnosis of tuberculosis in Rawalpindi, Pakistan. BMC research notes 2011, 4, 1-5.

59. Diagnostic, W. treatment delay in tuberculosis. An in-depth analysis of the health-seeking behaviour of patients and health system response in seven countries of the eastern mediterranean region. Regional Officer for the Eastern mediterranean, Cairo. World Health Organization 2006.

60. Courtwright, A.; Turner, A. N. Tuberculosis and stigmatization: pathways and interventions. Public health reports 2010, 125, 34-42.

61. Getnet, F.; Demissie, M.; Assefa, N.; Mengistie, B.; Worku, A. Delay in diagnosis of pulmonary tuberculosis in low-and middle-income settings: systematic review and meta-analysis. BMC pulmonary medicine 2017, 17, 1-15.

62. Osei, E.; Akweongo, P.; Binka, F. Factors associated with DELAY in diagnosis among tuberculosis patients in Hohoe Municipality, Ghana. BMC public health 2015, 15, 1-11.

63. Li, Y.; Ehiri, J.; Tang, S.; Li, D.; Bian, Y.; Lin, H.; Marshall, C.; Cao, J. Factors associated with patient, and diagnostic delays in Chinese TB patients: a systematic review and meta-analysis. BMC medicine 2013, 11, 1-15.

64. Marx, F. M.; Fiebig, L.; Hauer, B.; Brodhun, B.; Glaser-Paschke, G.; Magdorf, K.; Haas, W. Higher rate of tuberculosis in second generation migrants compared to native residents in a metropolitan setting in Western Europe. PloS one 2015, 10, e0119693.

65. Belkina, T. V.; Khojiev, D. S.; Tillyashaykhov, M. N.; Tigay, Z. N.; Kudenov, M. U.; Tebbens, J. D.; Vlcek, J. Delay in the diagnosis and treatment of pulmonary tuberculosis in Uzbekistan: a cross-sectional study. BMC infectious diseases 2014, 14, 1-8.

66. Stop, T. partnership: The potential impact of the COVID-19 response on Tuberculosis in high burden countries: A modelling analysis. 2020; 1-7. Available online: http://www.stoptb.org/assets/documentsnews/Modeling (accessed on 24.1. 2021). 